\title{
NILAI-NILAI YANG TERDAPAT DALAM FILM ANIMASI LORONG WAKTU EPISODE 1-10
}

\author{
Kurnia Ramadhanti Nurjannah $^{1)}$, Mudzanatun ${ }^{2}$, Fajar Cahyadi ${ }^{3)}$ \\ Universitas PGRI Semarang \\ Corresponding author Email: kurnia.ramadanti73@gmail.com
}

\begin{abstract}
Abstrak
Kata Kunci: Nilai moral, film animasi Lorong waktu

Latar belakang yang mendorong penelitian ini adalah menurunnya nilai moral pada anak usia sekolah dasar. Melalui hal tersebut, animasi Lorong Waktu diharapkan dapat menjadi acuan pendidikan moral melalui cara yang menyenangkan dengan cara menonton untuk meningkatkan nilai moral pada anak usia sekolah dasar. Fokus dalam penelitian ini adalah menemukan nilai moral yang terdapat dalam film animasi Loong Waktu episode 1-10. Tujuan yang hendak dicapai dalam penelitian ini adalah untuk menganalisis nilai moral dalam film animasi Lorong Waktu episode 1-10. Melalui penelitian ini, peneliti berharap dapat menyajikan nilai moral yang terdapat dalam film animasi Lorong Waktu episode 1-10. Jenis penelitian ini adalah penelitian kualitatif. Digunakannya metode kualitatif dalam penelitian ini adalah untuk mendapatkan data yang mendalam, suatu data yang diperoleh dari peristiwa yang terjadi dengan menggunakan beberapa metode yang ada. Data dalam penelitian ini diperoleh melalui wawancara, dokumentasi, serta metode pengamatan dan pencatatan. Berdasarkan hasil analisis film animasi Lorong Waktu episode 1-10 menunjukkan bahwa film tersebut memiliki nilai moral yaitu sikap hormat, bertanggungjawab, kejujuran, keadilan, toleransi, bijaksana, disiplin diri, suka menolong, berbelas kasih, kerja sama, berani dan demokratis. Kedua belas nilai moral yang menjadi acuan tersebar dan muncul disetiap adegan pada film animasi Lorong Waktu Episode 1-10.
\end{abstract}

\section{Abstract}

Keyword: Moral value, This research is the decline in moral values in elementary school age children. the animated film Lorong waktu Through this, the Lorong Waktu animation is expected to be a reference for moral education in a fun way by watching to increase moral values in elementary school age children. The focus of this research is to find the moral values contained in the animated film Loong Waktu episodes 1-10. The aim of this research is to analyze the moral values in the animated film Lorong Waktu episodes 1-10. Through this research, the researcher hopes to present the moral values contained in the animated film Lorong Waktu episodes 1-10. This type of research is qualitative research. The use of qualitative methods in this study is to obtain in-depth data, data obtained from events that occur using several existing methods. The data in this study were obtained through interviews, documentation, as well as observation and recording methods. Based on the analysis of the animated film Lorong Waktu episodes 1-10 show that the film has moral values, namely respect, responsibility, honesty, justice, tolerance, wisdom, self-discipline, helpfulness, compassion, cooperation, courage and democracy. The twelve moral values that are used as references are scattered and appear in every scene in the animated film Lorong Waktu Episodes 1-10. 


\section{Pendahuluan}

Pendidikan merupakan proses pembelajaran bagi peserta didik untuk dapat mengerti, paham dan membuat manusia lebih kritis dalam berpikir. Telah menjadi pengetahuan umum bahwa pendidikan adalah suatu bentuk investasi jangka panjang yang penting bagi seorang manusia dimasa depannya. Drijakara dalam Soegeng Ysh (2016:42) menyatakan pendidikan bertujuan untuk memanusiakan manusia, yaitu menjadikan manusia sebagai manusia; membentuk manusia seutuhnya, yaitu manusia terdidik, berpengetahuan luas dan mendalam, mampu mengembangkan dan mengendalikan emosinya, memiliki sikap dan kehendak yang kuat dan berketerampilan yang bermanfaat.

Penanaman pendidikan pada anakanak dimasa sekarang diperlukan kreatifitas yang tinggi bagi guru maupun orang tua. Selain pentingnya pemberian materi pembelajaran kepada anak, tentu saja penanaman pendidikan moral untuk membentuk karakter anak juga merupakan hal yang sangat penting bagi anak-anak. Pentingnya penanaman nilai-nilai moral sejak usia dini agar karakter anak dapat berkembang dengan potensi dan kemampuan anak secara optimal serta tumbuh sikap dan perilaku positif bagi siswa.
Namun pada kenyataannya dalam Muchson dan Samsuri (2015: 83), pendidikan di Indonesia dalam praktik pembelajarannya secara nyata lebih didominasi oleh pengembangan kemampuan intelektual saja dan kurang memberikan perhatian pada aspek moral. Padahal aspek moral dalam kehidupan sehari-hari bisa dikatakan sebagai salah satu elemen yang sangat penting. Seseorang dengan kemampuan intelektual yang tinggi bisa saja menjadi tidak berguna apabila tidak memiliki moral yang baik dalam dirinya, atau bahkan bisa saja membahayakan masyarakat apabila moralitasnya rendah. Bahkan saat ini menunjukkan maraknya berbagai kasus pelanggaran moral dalam kehidupan seharihari. Mirisnya, dari berbagai kasus tersebut tak sedikit yang melibatkan anak-anak dibawah umur.

Menurut Lickona dalam Lukmantoro (2018: 129) sikap hormat dan tanggung jawab adalah dua nilai dasar yang harus diajarkan di sekolah. Adapun contoh dari nilai moral yang lain adalah (1) kejujuran, (2) keadilan, (3) toleransi, (4) bijaksana, (5) disiplin diri, (6) suka menolong, (7) berbelas kasih, (8) kerja sama, (9) berani dan (10) demokratis. Nilainilai tersebut terbentuk dari sikap hormat dan tanggung jawab atau pelengkap tindakan yang dilakukan dengan sikap hormat dan tanggung jawab. 
Menurut Durkheim dikutip oleh Abdullah dan van der Leeden dalam Muchson dan Samsuri (2015: 85) sekolah mempunyai tugas dan peranan yang sangat besar dalam perkembangan moral peserta didik. Pendapat ini berbeda dengan anggapan umum yang menyatakan bahwa pendidikan moral terutama merupakan hak keluarga. Menurut pendapatnya meskipun keluarga merupakan lingkungan yang efektif untuk menumbuhkan perasaanperasaan mendasar tentang moralitas serta perasaan-perasaan dalam hubungan pribadi yang sederhana, namun keluarga bukan lembaga yang dibangun dengan tujuan mendidik anak untuk dapat memenuhi tuntutan-tuntutan masyarakat.

Penanaman nilai-nilai moral sejak dini sangat penting kepada anak untuk membekali mereka dalam kehidupan bermasyarakat, selain itu merupakan upaya membiasakan anak untuk menilai apa yang benar dan baik untuk mereka secara bijak. Soegeng Ysh (2015: 26) mengatakan bagaimanapun, pendidikan moral dalam kerangka pembentukan karakter yang baik harus berupaya agar pengetahuan moral, perasaan moral, dan tindakan moral bersinergi, saling mendukung, menjadikan anak tahu, mau dan melakukan.

Pada era modern ini, membangun moral pada anak dapat dilakukan dengan banyak cara. Hal ini bisa dilakukan dengan cara memasukkan penanaman moral tersebut dalam kegiatan sederhana pada kehidupan sehari-hari. Misalnya seperti membiasakan anak-anak untuk bersikap sopan, menghormati orang yang lebih tua dan lain-lain. Kegiatan yang menjadi kesukaan anak pada saat ini adalah menonton televisi yaitu kegiatan melihat dipadukan mendengarkan. Pada kegiatan ini anak-anak mengamati dan meniru apa yang dilihatnya di televisi. Seiring dengan semakin majunya dunia perfilman di Indonesia, tentu saja banyak memberikan referensi tayangan-tayangan di televisi setiap harinya, salah satunya adalah film animasi.

Film adalah produk media masa yang sangat populer saat ini. Film juga menjadi media hiburan yang mempunyai tempat tersendiri bagi khalayak dibanding dengan media massa lainnya. Tak hanya menyuguhkan alue cerita yang menarik, namun juga gambar dan efek suara yang menrik sehingga membuat film tidak pernah membuat bosan untuk dinikmati. Film merupakan salah satu bukti ketinggian akal manusia dalam menciptakan teknologi komunikasi dan informasi. Film pada awalnya merupakan hiburan namun oleh karena dikonsumsi secara terus menerus pada akhirnya menjadi seperti kebutuhan primer manusia. Dalam film-film terdapat adegan-adegan ataupun karakter dan perilaku tokoh yang sering dijadikan referensi bagi para penontonnya. Insan 
perfilman harus mampu menciptakan film yang sarat nilai, bukan yang bebas nilai yang sekedar ingin "meraup" keuntungan. Hal ini karena pada dasarnya setiap perilaku, sikap dan pendirian dasar yang dimiliki oleh para tokoh dalam film mengandung nilai-nilai yang sering ditiru oleh penontonnya (Basirudin, 2010: 12)

Menurut UU Nomor 35 Tahun 2014 tentang perlindungan anak pasal 6 disebutkan bahwa setiap anak berhak beribadah menurut agamanya, berpikir, dan berekspresi sesuai dengan tingkat kecerdasan dan usianya dalam bimbingan orangtua atau wali. Hal ini berarti orang tua memiliki peran yang sangat penting terhadap pemilihan tayangan yang cocok dan sesuai dengan anak yang memberikan pengaruh positif terhadap anak-anak tersebut.

Sayangnya, beberapa tayangan televisi yang diputar cenderung mengandung unsur negatif. Seperti dalam film kartun atau animasi yang menanyangkan adegan / kekerasan, pertengkaran dan pelanggaran sosial yang tentu saja tidak pantas ditonton oleh anakanak. Film tak hanya merupakan media hiburan yang luar biasa, tetapi film juga memberikan semacam rasa kehadiran dan kedekatan dengan suatu dunia yang tak tertandingi dengan tempat lain, dunia yang tak terbayangkan. Menonton film dapat membawa penonton keluar dari kehidupan sehari-hari mereka dan serasa berada di dunia yang berbeda. Film sebagai media komunikasi massa memiliki peran yang sangat penting yaitu sebagai alat penyalur pesan kepada penonton. Pesan tersebut dapat berupa pesan positif maupun negatif.

Menurut Kenny dikutip oleh Nurgiyantoro dalam Rohmah (2016 :20-21) nilai moral dalam cerita biasanya dimaksudkan sebagai suatu sasaran yang berhubungan dengan ajaran moral tertentu yang bersifat praktis, yang dapat diambil dan ditafsirkan lewat cerita yang bersangkutan oleh pembaca. Nilai moral merupakan pertunjuk yang sengaja diberikan oleh pengarang tentang berbagai hal yang berhubungan dengan masalah kehidupan, seperti skipa, tingkah laku dan sopan santun pergaulan, disampaikan lewat cerita ataupun lewat sikap dan tingkah laku tokohnya. Salah satu film yang digemari oleh anak-anak adalah film animasi, karena dalam film animasi dikemas dalam suasana humor yang menarik. Salah satu contohnya adalah serial animasi berjudul "Lorong Waktu" yang di produksi oleh CookIt Studio yang tayang perdana pada $11 \mathrm{Mei}$ 2019. Lorong Waktu merupakan sebuah serial televisi animasi Indonesia tahun 2019 yang disiarkan di saluran SCTV. Serial tersebut merupakan adaptasi dari sinetron tahun 1999 yang memiliki judul sama. Serial animasi ini mengisahkan tentang petualangan Zidan, Haji Husin, dan Ustadz 
Addin yang berkeliling menjelajah waktu dengan mesin waktu yang ditemukan oleh Ustadz Addi. Serial tersebut mengisahkan tentang petualangan Zidan, Haji Husin dan Ustadz Addin yang berkeliling menjelajah waktu yang di mesin waktu yang ditemukan oleh Ustadz Addin. Dimana mereka terkadang mengahadapi beberapa masalah dan menyelesaikannya dengan baik. Selian alur ceritanya yang menarik, dalam film animasi ini juga terdapat beberapa pesanpesan dalam setiap episodenya.

Berdasarkan permasalahan di atas, peneliti tertarik untuk menganalisis nilainilai moral yang terdapat dalam film animasi "Lorong Waktu", sehingga penulis memilih judul "Nilai-Nilai Moral Yang Terdapat Dalam Serial Animasi Lorong Waktu Episode 1-10”. Alasan peneliti ingin menganalisis film animasi tersebut karena hal-hal yang ditayangkan dalam sebuah film dapat mempengaruhi perkembangan anak khususnya perkembangan moral. Hal ini didukung penelitian yang dilakukan oleh Ririn Layfatul Munawaroh dari Universitas PGRI Semarang dalam penelitiannya yang berjudul "Nilai Karakter dalam Film Animasi "Hoston Hears A Who" Sudut Pandang Siswa Sekolah Dasar" yang menyatakan bahwa dalam memberikan Pendidikan karakter dan moral dapat dilakukan dengan menggunakan cara yang disukai siswa yaitu melalui menonton film. Oleh karena itu, adanya pesan moral dalam film sangatlah penting untuk dikaji sehingga khalayak dapat diberikan gambaran mengenai pesan moral dibalik film yang ditonton.

\section{Metode Penelitian}

Penelitian ini menggunakan pendekatan kualitatif karena penelitian ini ingin memberikan gambaran nilai-nilai moral yang terkandung dalam Film Animasi Lorong Waktu secara rinci. Penelitian deskriptif merupakan penelitian non eksperimen, tempat penelitian yang dilakukan tidak di lapangan. Setting penelitian berkenan dengan penentuan unit, bagian, kelompok, dan tempat orang-orang yang terlibat di dalam kegiatan atau peristiwa yang ingi diteliti. Tempat penelitian ini dengan mengkaji dan mengumpulkan sumber dan kajian kepustakaan, dengan kata lain penelitian ini dilakukan di atas meja. Subjek dalam penelitian ini adalah Peserta didik dan Guru kelas V SD N 02 Ngawen yaitu Siti Umi Kalsum, S.Pd. Penelitian ini akan menggali data mengenai nilai-nilai moral yang terdapat dalam film animasi Lorong Waktu, maka sumber data dalam penelitian ini berupa literatur-literatur. Adapun prosedur pengumpulan data yang digunakan adalah wawancara, dokumentasi dan pengamatan dan pencatatan data. 


\section{Hasil Penelitian dan Pembahasan}

Film yang menjadi data penelitian ini adalah film animasi Lorong Waktu karya . Film animasi Lorong Waktu sendiri terdiri dari beberapa episode yang memiliki alur cerita yang kreatif. Peneliti memilih 10 episode untuk dianalisis nilai-nilai moral yang terkandung dalam setiap episodenya. Film ini diangkat dari sinetronnya terdahulu yang memiliki judul yang sama yaitu Lorong Waktu. Film ini merupakan satusatunya film animasi Indonesia yang mengangkat fikso ilmiah religi. Film animasi Lorong Waktu pertama kali bergabung dengan Youtube pada tanggal 12 Mei 2019 dan sudah ditonton sebanyak lebih dari satu juta penonton/dengan subscriber sebanyak dua ratus dua puluh enam ribu ribu orang. Film animasi Lorong Waktu juga sempat ditayangkan pada beberapa chanel televisi Indonesia yaitu MNCTV dan SCTV.

Analisis film animasi Lorong Waktu berupa soft copy film animasi Lorong Waktu . gambar Tindakan serta kalimat pernyataan yang mengandung nilai-nilai moral. Pengumpulan data dilakukan dengan metode simak catat dengan mengisi table analisis nilai moral yang sesuai dengan instrument penelitian. Data tersebut dianalisis dan deskripsi sesuai dengan nilai moral yang ada pada setiap adegan pada film animasi Lorong Waktu.
Temuan hasil penelitian pada film animasi Lorong Waktu dalam penelitian ini meliputi nilai-nilai moral yang terdapat dalam setiap episode. Dimana setiap episode memberikan pesan diakhir cerita film yang sangat positif dan bermanfaat bagi penonton. Hal ini seperti pada tayangan awal berjudul "Zidan Rindu Kakek" dimana terdapat adegan Zidan yang akan pamit kepada pak Haji dan pak Ustadz Addin lalu pak Haji berkata "Makenye kita harus menepati janji, janji pulang pada waktunya ya pulang." Dimana pak Haji mengajarkan kepada Zidan agar selalu menepati janjinya. Film ini sangat cocok untuk memotivasi anak-anak agar menjadi pribadi yang lebih baik. Oleh karena itu, film ini layak dijadikan sebagai sarana Pendidikan.

Table 1. Rekap Nilai Moral yang Muncul dalam Film Animasi Lorong Waktu Episode 1-10

\begin{tabular}{ccc}
\hline No. & Nilai Moral & Episode \\
\hline 1. & Sikap Hormat & 6,10 \\
\hline 2. & Tanggung Jawab & 1 \\
\hline 3. & Kejujuran & 3,5 \\
\hline 4. & Keadlian & 8 \\
\hline 5. & Toleransi & 4 \\
\hline 6. & Bijaksana & $2,3,5,7,8$, \\
& & 9 \\
\hline 7. & Disiplin Diri & $6,8,9$ \\
\hline 8. & Suka Menolong & $1,2,3,10$ \\
\hline 9. & Berbelas Kasih & 4,6 \\
\hline 10. & Kerja Sama & 2,7 \\
\hline 11. & Berani & 8 \\
\hline 12. & Demokrasi & 6 \\
\hline
\end{tabular}


Berdasarkan hasil analisis nilai moral yang terkandung dalam film animasi Lorong Waktu episode 1-10 menunjukkan bahwa terdapat beberapa tokoh yang paling sering menunjukkan nilai moral dalam setiap episodenya, baik itu nilai moral positif atau nilai moral negatif. Salah satu tokoh yang terkadang menampilkan nilai moral negative seperti bertingkah kurang sopan adalah tokoh Zidan, hal ini karena Zidan yang masih tergolong sebagai anakanak oleh karena itu terdapat tokoh lain yang berperan sebagai pembimbing bagi Zidan yang menonjolkan nilai moral positif. Tokoh tersebut adalah tokoh Pak Haji dan Ustadz Addin dimana kedua tokoh tersebut digambarkan sebagai tokoh yang bijaksana. Bijaksana sendiri merupakan salah satu nilai moral positif dari kedua belas nilai moral yang disebutkan oleh Lickona. Menurut Lickona dalam Lukmantoro (2018: 129) sikap hormat dan tanggung jawab adalah dua nilai dasar yang harus diajarkan di sekolah. Adapun contoh dari nilai moral yang lain adalah (1) kejujuran, (2) keadilan, (3) toleransi, (4) bijaksana, (5) disiplin diri, (6) suka menolong, (7) berbelas kasih, (8) kerja sama, (9) berani dan (10) demokratis. Nilainilai tersebut terbentuk dari sikap hormat dan tanggung jawab atau pelengkap tindakan yang dilakukan dengan sikap hormat dan tanggung jawab.
Berdasarkan wawancara yang dilakukan peneliti dengan guru kelas V SD N Ngawen 2 Blora, Ibu Umi Kalsum, S.Pd dan peserta didik mengenai film animasi Lorong Waktu bahwa film ini dapat memberikan gambaran nilai moral yang dapat dijadikan contoh pembelajaran terhadap anak. Film ini memiliki alur cerita positif yang sangat baik untuk ditayangkan kepada anak-anak usia sekolah dasar. Tidak ada alur cerita negatif dalam film ini sehingga mampu memberikan manfaat yang maksimal apabila anak-anak menontonnya.

Ditinjau dari jumlah penonton dari kanal youtube resmi film animasi Lorong Waktu yang kini telah memiliki dua ratus dua puluh enam ribu subscriber, dalam setiap episodenya rata-rata film animasi Lorong waktu ditonton sekitar serratus lima puluh ribu penonton dalam setiap episodenya. Hal ini menunjukkan bahwa film animasi Lorong waktu memiliki banyak peminat meskipun penayanganya lewat aplikasi youtube.

\section{Kesimpulan}

Berdasarkan hasl penelitian analisis nilai moral yang terkandung dalam film animasi Lorong Waktu episode 1-10 dapat disimpulkan bahwa film tersebut mengandung dua belas nilai moral didalamnya yang meliputi (1) sikap hormat, 
(2) tanggung jawab, (3) kejujuran, (4) keadilan, (5) telorensi, (6) bijaksana, (7) disiplin diri, (8)suka menolong, (79 berbelas kasih, (10) kerja sama, (11) berani dan (12) demokratis.

Berdasarkan keseluruhan hasil analisis nilai moral yang terkandung dalam film animasi Lorong Waktu episode 1-10 yang dijadikan acuan serta hasil wawancara Bersama guru dan peserta didik, maka film animasi Lorong Waktu layak dijadikan sebagai contoh memberikan nilai moral sejak dini. Oleh karena itu, guru bisa menggunakan film animasi Lorong Waktu sebagai sarana pembelajaran nilai moral yang cocok diberikan untuk anak-anak agar anak dapat meniru nilai-nilai moral yang baik yang terkandung dalam film tersebut dan menerapkannya dalam kehidupan sehari-hari.

Berdasarkan hasil simpulan di atas, maka peneliti memiliki saran untuk guru agar mampu memberikan motivasi dan menanamkan nilai moral pada siswa melalui film khusus anak-anak. Bagi orangtua sebaiknya mampu memanfaatkan film animasi Lorong Waktu sebagai wawasan untuk anak serta media untuk membina moral anak. Melalui hasil penelitian ini diharapkan siswa memiliki contoh untuk menjadi pribadi yang bermoral dan hebat dengan tayangan film yang mendukung seperti film animasi Lorong Waktu.

\section{Daftar Pustaka}

AR, Muchson dan Samsuri. 2015. Dasar-Dasar Pendidikan Moral (Basis Pengembangan Pendidikan Karakter. Yogyakarta. Penerbit Ombak.

Basirudin. 2010. 'Nilai-Nilai Moral Dalam Film Serial Kartun Upin dan Ipin”. Skripsi. STAIN PURWOKERTO.

Lukmantoro, Dhanang. (2018). “Analisis Nilai Moral Dalam Film Animasi "The Boss Baby" Produksi Dreamworks Animation Bagi Siswa Sekolah Dasar". Jurnal Filsafat Indonesia. Vol 1 No3.

Munawaroh, Ririn Layfatul dan Singgih Adhi Prasetyo. 2019. 'Nilai Karakter dalam Film Animasi "Horton Hears A Who" Sudut Pandang Siswa Sekolah Dasar. Indonesian Values and Character Education Joumal. Vol 2 No 1.

Rohmah, Miftahur. 2016. 'Nilai Moral Kemanusiaan Dalam Teks Film La Rafle Karya Roselyn Bosch". Skripsi. Universitas Negeri Yogyakarta. Republic Indonesia. 2014. Undang-Undang Nomor 35 Pasal 6 Tahun 2014 tentang Perlindungan Anak. Lembaran Negara RI tahun 2014, No. 297. Sekretariat Negara. Jakarta.

Soegeng Ysh, A.Y. 2015. Etika Pancasila Nilai-nilai Pembentuk Karakter. Yogyakarta. Magnum PustakaUtama.

Soegeng Ysh, A.Y. 2016. Landasan Kependidikan. Yogyakarta. Magnum Pustaka Utama. 